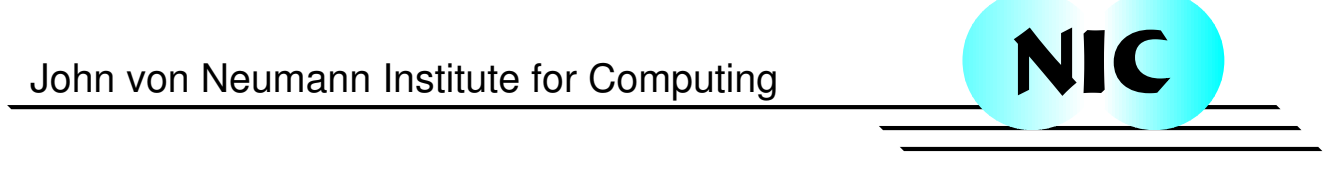

\title{
Adsorption of Polyacrylic Acid on Aluminium Oxide: DRIFT Spectroscopy and Ab Initio Calculations
}

\author{
H. Lewandowski, E. Koglin
}

published in

Modern Methods and Algorithms of Quantum Chemistry, J. Grotendorst (Ed.), John von Neumann Institute for Computing, Jülich, NIC Series, Vol. 2, ISBN 3-00-005746-3, p. 19, 2000.

(C) 2000 by John von Neumann Institute for Computing

Permission to make digital or hard copies of portions of this work for personal or classroom use is granted provided that the copies are not made or distributed for profit or commercial advantage and that copies bear this notice and the full citation on the first page. To copy otherwise requires prior specific permission by the publisher mentioned above.

http://www.fz-juelich.de/nic-series/ 


\title{
Adsorption of Polyacrylic Acid on Aluminium Oxide: DRIFT Spectroscopy and Ab Initio Calculations
}

\author{
H. Lewandowski and E. Koglin \\ Institute of Applied Physical Chemistry (ICG-7), Research Center Juelich, \\ D-52425 Juelich, Germany
}

\begin{abstract}
Diffuse reflectance Fourier transform infrared (DRIFT) spectroscopy was used to study the adsorption process of the water-soluble polyacrylic acid (PAA) polymer on hydrous $\delta-\mathrm{Al}_{2} \mathrm{O}_{3}$. Vibrational assignment of PAA, sodium polyacrylate (Na-PA) and the PA-oxide surface complex was achieved by comparison of observed band position and intensity in the DRIFT spectra with wavenumbers and intensities from ab initio quantum mechanical calculations. The presented data of polyacrylic acid suggest that IR data calculated ab initio on relatively short oligomers may provide valuable information regarding the interpretation of polyelectrolyte infrared spectra.

Batch experiments were performed to adsorb PAA onto the $\delta-\mathrm{Al}_{2} \mathrm{O}_{3}$ surface. The results obtained from DRIFT studies were compared with adsorption isotherm experiments in order to relate the level of PAA coverage to the nature of the surface complex. Ab initio molecular orbital calculations on PAA/ $/ \mathrm{Al}_{2} \mathrm{O}_{3}$ clusters were used to model possible surface complexes. Strong correlation were found between theoretical and observed DRIFT frequencies of the antisymmetric R-COO vibration. A number of possible configurations of the polyacrylic acid/aluminate surface complex were tested via ab initio calculations. These possible configurations included different di-aluminium octahedral $\mathrm{Al}^{3+}$ surface models. Results obtained from adsorption isotherm experiments, DRIFT spectra and ab initio calculations indicate that the carboxylate oxygens bridge an $\mathrm{Al}^{3+}$-octahedral dimer $\left[\mathrm{Al}_{2}(\mathrm{OH})_{2} \bullet 4\left(\mathrm{H}_{2} \mathrm{O}\right) 2(\mathrm{OH})\right]$ in a ligand-exchange inner-sphere complex.
\end{abstract}

